\title{
Risk interdependency, social norms, and wildfire mitigation: a choice experiment
}

\author{
Katherine L. Dickinson ${ }^{1}$ (D) . Hannah Brenkert-Smith ${ }^{2} \cdot$ Greg Madonia $^{3}$. \\ Nicholas E. Flores ${ }^{4}$
}

Received: 9 April 2019 / Accepted: 26 April 2020 / Published online: 5 June 2020

(C) The Author(s) 2020

\begin{abstract}
Wildfire presents a growing threat across the American West. We conducted an online choice experiment in Western Colorado to assess how social interactions affect wildfire mitigation decisions through two distinct pathways: risk interdependency (neighbors' conditions affect perceived wildfire risk) and social norms (neighbors' actions affect perceptions of appropriate mitigation choices). In contrast to key observational studies, we find that participants are less likely to choose to mitigate when they have more neighbors with sparse vegetation. This effect operates through the risk interdependency pathway: sparse vegetation on neighboring properties lowers participants' wildfire risk perceptions and appears to be viewed as a substitute for one's own mitigation actions. In this context, where neighbors are nameless and faceless, social norms do not counteract this negative effect. To reconcile this experimental result with observational studies, we discuss how both risk interdependency and social norms are influenced by geographical and social contexts and highlight how these insights can inform future research and policy action.
\end{abstract}

Keywords Wildfire $\cdot$ Risk mitigation $\cdot$ Social interactions $\cdot$ Social norms

\section{Introduction}

In the face of increasing wildfire hazards, actions that homeowners take to reduce fire risk on private property are crucial. Our research examines how and why the mitigation behaviors of people living in the wildland-urban interface (WUI) may be affected by conditions on neighbors' properties. Prior research has highlighted two key processes that explain

Katherine L. Dickinson

katherine.dickinson@cuanschutz.edu

1 Environmental and Occupational Health, Colorado School of Public Health, 13001 E 17th Pl, Campus Box B119, Aurora, CO 80045, USA

2 Environment and Society Program, Institute of Behavioral Science, University of Colorado Boulder, 483 UCB, Boulder, CO 80309, USA

3 Economics, California State University Chico, Butte Hall, Room 603, Chico, CA 95929-0430, USA

4 Economics, University of Colorado Boulder, UCB 256, Boulder, CO 80309, USA 
interconnected wildfire mitigation decisions. First, wildfire ignores property lines, such that the fuel conditions on one property affect wildfire risk for surrounding homes (Shafran 2008). Second, people care about what their neighbors think of them and may face (tangible or intangible) social rewards or penalties for their mitigation actions. Prior observational studies have found associations between homeowners' wildfire mitigation decisions and neighbors' mitigation choices (Brenkert-Smith et al. 2013; Dickinson et al. 2015; Brenkert-Smith 2010, 2011). However, it is difficult to separate causal social effects from other explanations for common patterns of behavior within social groups, such as shared characteristics or influences (see Manski 1993). To further explore these pathways in an experimental setting, we conducted online choice experiments that allowed us to tightly control the conditions under which mitigation choices were made and to conduct rigorous tests of the effects of others' behavior on these decisions. By conducting these experiments with homeowners currently living in fire-prone areas and by collecting a rich set of data on homeowners' knowledge, attitudes, behaviors, and motivations for these behaviors, we are able to examine how these real-world characteristics and experiences influence responses to changing social conditions in the experiments.

\section{Background}

In the past fifteen years, WUI areas throughout the USA have incurred increased economic and social costs due to wildfire. The past few years have seen record-breaking fire seasons across the country. The fire season of 2017 was noteworthy for the high number of acres burned (over 10 million acres from more than 71,000 fires across the USA) (NIFC.gov 2017b), and for the air quality impacts and health advisories resulting from wildfire smoke that particularly impacted the American West (Reid et al. 2016). The subsequent year, 2018, rewrote history with the worst WUI disaster in recent years. The Camp Fire in Paradise, CA, resulted in 85 fatalities, destroyed nearly 19,000 structures across 153,000 acres, and resulted in the evacuation of 52,000 homes. The fall of 2019 brought another series of catastrophic fire events across California. These events have focused renewed attention to the conditions in wildland-urban interface communities, and to decisions made by those most vulnerable to direct wildfire impacts (Sagat 2018).

Just as US record books have been repeatedly rewritten in recent years, Colorado saw its own series of record-breaking fire events in 2012 and 2013. In the summer of 2012, Colorado saw almost a quarter million acres burn as conditions across the Rockies were perfect for high wildfire risk (i.e., hot, dry, and windy) (NOAA 2012). June of that year was the hottest on record in the state; in that month, the High Park fire started outside of Fort Collins, CO, destroying 259 homes, and Colorado Springs' Waldo Canyon fire destroyed 346 homes. Just a year later, in June of 2013, records were broken yet again when the Black Forest fire became the most destructive fire in state history, causing two fatalities, the evacuation of 38,000 people, and the destruction of 509 homes. While these types of wildland-urban interface disasters are more common on the state's Front Range, Colorado's Western Slope has also seen active fire seasons exacerbated by extremely dry winters and ongoing high temperatures. Rapid development (Radeloff et al. 2010) and drought (Westerling and Swetnam 2003) have added to the fire risk in this region. These factors and climate-related changes in wildfire behavior are associated with longer fire seasons and larger fires (Dennison et al. 2014), more houses burned (Hammer et al. 2009), and congressional annual appropriations for fire suppression pushing over \$2 billion (NIFC.gov 2017a). 
While actions at multiple scales are required to effectively reduce the risk of wildfire, homeowners' decisions in fire-prone areas play a central role in shaping wildfire occurrence and related impacts. The purpose of this research is to gain a better understanding of those decisions, and specifically, how interactions between neighbors in the WUI shape risk mitigation choices. Conceptually, there are several pathways through which the actions of neighbors and other social contacts can influence homeowners' decisions about whether and how to take action to reduce wildfire risk. These include information transmission and learning effects [e.g., learning about wildfire risk and mitigation options (McCaffrey et al. 2011; Dickinson et al. 2015)], and effects on how risks are interpreted [e.g., social amplification of risk (Brenkert-Smith et al. 2013; Kasperson et al. 1988)]. For the purposes of this paper, we focus on two social interaction pathways: risk interdependency and social norms. While these are not the only channels through which neighbors can affect each others' mitigation choices, they are particularly relevant in the wildfire context, and the interaction between these effects in particular has been understudied. To our knowledge, no single study has explicitly addressed both processes in the context of wildfire mitigation decisions. Our approach is thus unique in that we recognize the (potentially interactive) roles that these processes play in shaping fire mitigation choices, and, crucially, in that our methods allow us to separately identify each of these roles, albeit in an experimental, stated preference context. In this section, we review relevant strands of the risk interdependency and social norms literatures, specifically as they relate to risk-related decision making in the face of wildfire and other natural hazards.

\subsection{Risk interdependency}

A key feature of the wildfire problem is that the rate at which a fire spreads, the potential devastation of a fire, and sometimes the likelihood of ignition are shaped by one's own decisions and actions, as well as those of neighboring land owners. Thus, one property owner's safety is dependent on other community members' actions to reduce wildfire risk. We refer to this phenomenon as risk interdependency throughout this paper; closely related terms used in prior studies include interdependent security (Kunreuther and Heal 2003) and risk externalities (Shafran 2008). For example, Kunreuther and Heal (2003) developed games in which the risk of experiencing a loss depended on the mitigation or risk averting actions of multiple players. These models illustrate the potential for sub-optimal collective outcomes: while the "all-invest" outcome is the Pareto optimum, individual utility-maximizing agents may not find it in their interest to invest unilaterally, leading to a sub-optimal equilibrium in which no one mitigates. However, if enough agents can be induced to invest, the system has the potential to tip from the inefficient to the efficient equilibrium (Schelling 1978).

Linking this risk interdependency concept to the wildfire context, Shafran (2008) developed a theoretical model, which is discussed in more detail in the next section, leading to the insight that the effect of neighbors' mitigation on a household's own mitigation behavior depends on whether own and neighbors' actions are viewed as strategic complements or substitutes. Specifically, under strategic complementarities, the benefits of one's own mitigation increase when more neighbors mitigate, while strategic substitutes imply that the benefits of one's own mitigation decrease as neighbors' mitigation increases. Empirically, Shafran finds a positive relationship between own and neighbors' mitigation levels in Colorado, interpreting this as evidence of strategic complementarities. Building on Shafran's work, Taylor (2015) conducted a similar analysis for 35 communities in Nevada with 
different vegetation types, and found evidence of strategic complementarity for three of these (sagebrush, pinyon-juniper, and alpine forest) while no risk interdependency effects were observed in grassland communities. In both of these studies, results were attributed to risk interdependency, and the possibility that households were imitating their peers' behaviors or responding to social pressure to "do their part" to reduce fuel loads in the community was not discussed. Warziniack et al. (2019) conducted a spatial spillover analysis using a dataset that paired professionally assessed wildfire risk with social survey data in Southwestern Colorado, finding that parcels with well-mitigated defensible space tended to be close to other parcels with well-maintained defensible space, while parcels with overgrown or dense vegetation within their defensible space are similarly situated near like parcels. Further, matched social surveys indicate that respondents who report working and talking with neighbors about wildfire risk also report having more defensible space. Consistent with previous studies described, however, the timing, direction, or mechanism of influence remains unknown. Indeed, in an observational study, disentangling these effects is quite difficult.

Experimental studies offer an alternative way of exploring risk interdependency, avoiding some of the identification problems inherent in observational studies. A subsequent study by Shafran (2010) constructed a set of experimental games in which subjects decided whether or not to pay to reduce the risk of a loss, the probability of which depended on the actions of other players in the game. Shafran observed behaviors in three different versions of the game, two of which involved different subsidy schemes intended to change the incentives for choosing mitigation. Results revealed that subjects rarely coordinated on the efficient equilibrium. Introducing subsidies for some or all players did increase mitigation levels, but in this application players rarely achieved the optimal "all-invest" solution. Subsequent studies have explored these effects further, for example, by examining spatial vs non-spatial dependency structures and stochastic vs deterministic outcomes (Kroll and Shafran 2017).

The role of risk interdependency in shaping decisions has also been explored in the context of other types of hazards. Kunreuther et al. (2004) present a conceptual model in the context of households' decisions to invest in protection against an earthquake. A household can make improvements to the structure of its own house, but if a neighboring house does not make these improvements, it may collapse and cause serious damage to one's own property. Thus, the incentive to invest decreases as the number of other players who do not invest in protection increases. Complementing this conceptual model, Meyer (2008, 2010) constructed laboratory experiments that used computer-based visual games to examine households' protective decisions in the face of earthquakes and hurricanes. However, these games did not explicitly incorporate risk interdependency, but were focused instead on understanding learning processes and, to some extent, the role of social norms. For example, Meyer (2008) found that respondents had a tendency to mimic local group norms in earthquake preparedness investment levels.

\subsection{Social norms and hazard mitigation}

Despite receiving relatively little systematic attention in the context of wildfire and other natural hazards, social norms represent a second key pathway through which neighbors' behaviors can affect a household's risk mitigation choices. Social norms refer to that which is socially sanctioned (Cialdini et al. 1991), which can both refer to common behaviors (Kallgren et al. 2000) and actions that receive approval or disapproval (Cialdini et al. 1990). 
For our purposes, social norms refer to a wide array of different processes and mechanisms through which individuals assign value to different actions by observing and engaging with other members of social groups. Friends, relatives, neighbors, and co-workers function as sources of influence in the dynamic process through which hazard-related decisions are made (Short 1984; Lion et al. 2002), and interactions within these social groups provide venues in which people test the "appropriateness" of their actions in terms of agreement with persons with differing levels of importance in their social environment (Turner et al. 1980; Fishbein and Ajzen 2010). In contrast to rational choice models, the Appropriateness Framework takes social processes and mechanisms into account, asserting that decision making in social dilemmas is guided by an interpretation of the situation through the interaction of various social processes, including one's identity and situational cues. It is this interpretation that sculpts decision making by defining whether, for example, the situation is cooperative or competitive. Subsequently, this definition prescribes a choice set (Weber et al. 2004). Norms and social learning may be particularly important when the physical environment is undergoing rapid change and changing levels of risk (Wolfe 1993).

Recent research specific to wildfire has begun to highlight the role informal social interactions play in shaping understandings of wildfire risk and appropriate actions to reduce risk (Brenkert-Smith 2010), the influence of talking about wildfire risk with neighbors on mitigation outcomes (Brenkert-Smith 2011; Dickinson et al. 2015), and the relative influence of formal versus informal interactions and sources of information on wildfire risk perception (Brenkert-Smith et al. 2013). One channel through which norms may shape mitigation choices is via socially constructed preferences for more or less dense vegetation. For example, Nelson et al. (2005) found that interview respondents preferred a "natural" look to their forest and that private property management decisions were informed by desire to maintain privacy, wildlife, aesthetics, and recreation. Meanwhile, Meldrum et al. (2018) found that about a fifth of survey respondents would not change how their property looked in order to reduce wildfire risk.

Despite evidence that social norms may shape risk mitigation choices in multiple ways, quantifying this role and identifying the mechanisms through which norms operate is difficult in observational studies. For example, previous work has shown that certain types of interactions, such as talking with neighbors about wildfire, are positively related to reported mitigation actions (Dickinson et al. 2015). However, from this observation alone it is unclear whether interactions cause increases in mitigation, or whether individuals who tend to mitigate also tend to interact more with their neighbors. There is an extensive literature discussing the statistical and conceptual challenges involved in distinguishing causal social effects from other explanations for consistent patterns of outcomes within social groups (Manski 1993; Soetevent 2006; Brock and Durlauf 2001).

Once again, experiments and quasi-experiments can be useful in overcoming some of these challenges. Within the broad literature on social norms, recent evidence has highlighted social comparisons as a relevant mechanism that may induce homeowners to change their behaviors. The question is whether households will feel social pressure to increase their level of mitigation when they observe that others in their community are also mitigating. Fischbacher et al. (2001) tested this "conditional cooperation" hypothesis in a set of laboratory experiments and found that about half of their participants increased their contribution to a generic "public good" as the contribution levels of other players increased. Several subsequent studies have designed field experiments around a similar set of hypotheses, examining the effects of social comparisons on contributions to charity (Frey and Meier 2004) and public radio (Croson and Shang 2008), energy conservation (Ayres et al. 2012; Allcott 2011), and water conservation (Ferraro and Price 2013). In the 
latter case, Ferraro and Price (2013) conducted a study in which 100,000 households in Cobb County, GA, were randomly assigned to three treatment groups that received different types of messages along with their utility bills. The first group received a "tip sheet" with technical information on ways to save water, while the second group received the tip sheet along with a message intended to appeal to "pro-social preferences." This message included phrases like, "We all have to do our part," and "We need your help." Finally, the third group's message included a social comparison: information was provided on the household's own consumption over a prior period and the average water use among neighbors, along with a message that said, "You consumed more water than XX\% of your Cobb County neighbors." [The study's authors cite Cialdini et al. (2006) and Schultz et al. (2007) in their choice of this negative frame.] Results indicate that the social comparison group reduced water use more than the other two groups, with these social norm effects being largest among households that previously used more water than average.

While we have thus far presented risk interdependency and social norms as two separate pathways through which the behaviors of one's neighbors can affect one's own mitigation choice, we note that these pathways may interact. Indeed, in the real world, these effects are operating simultaneously and dynamically to influence mitigation outcomes. A rich literature spanning the social sciences has put forth a variety of mechanisms through which societies and communities can encourage (or coerce) individuals to contribute to the public good and achieve successful collective outcomes through social norms (e.g., Ostrom 1990, 2000; Sethi and Somanathan 1996). By raising costs for individuals that fail to invest, social norms can help to solve the problems inherent in interdependent risk contexts, helping to tip communities toward the efficient outcome. Recent policy efforts in the wildfire context are based on this premise, making this a particularly relevant context in which to explore interactions between risk interdependency problems and social norms. With the passage and implementation of the Healthy Forests Restoration Act in 2003, Community Wildfire Protection Plans (CWPPs) have become the dominant management strategy, and the central goal of this policy is to create incentives for communities to understand the interdependent nature of wildfire risk and adopt collaborative risk reduction strategies. These community-focused goals have since been solidified through the creation of Fire Adapted Communities, as one of three pillars in the National Cohesive Strategy (Council 2014).

\section{Model}

Drawing on this background, we develop a simple conceptual model to describe homeowners' wildfire mitigation choices. We begin with Shafran's (2008) risk interdependency model, and then supplement this model to include social norms.

\subsection{Shafran's risk externality model}

Each of $N$ agents living in a WUI community has income $Y$ and faces a risk of loss $L$ if a wildfire destroys their house. (In this model, there are no partial losses.) $P$, the probability that the house is destroyed by wildfire, depends on the agent's defensible space $\left(a_{i} \in \mathbb{R}^{+}\right)$, a weighted average of defensible space choices of neighboring homeowners $\left(n_{i}=\sum_{j \neq i} w_{i j} a_{j}\right)$, and other relevant risk factors $\left(X_{i}\right)$ : 


$$
P=P\left(a_{i}, n_{i}, X_{i}\right)
$$

The cost of defensible space is $c$ per unit of defensible space created. Agents choose the amount of defensible space to maximize utility, defined as expected consumption of a composite good equal to income minus the cost of defensible space and expected wildfire losses:

$$
U=Y-c a_{i}-P\left(a_{i}, n_{i}, X_{i}\right) L
$$

Given this model, the first-order condition for utility maximization is:

$$
c=-P_{1}\left(a_{i}, n_{i}, X_{i}\right) L
$$

where $P_{1}$ is the first derivative of the probability function with respect to $a_{i}$. (Shafran shows that the choice of $a_{i}$ that satisfies this equation will be inefficient compared with the socially optimal level of defensible space that optimizes the sum of all homeowners' utility functions.)

Here, we are primarily interested in the effect of a change in neighbors' defensible space on an agent's own mitigation decision. This is given by:

$$
\frac{d a_{i}}{d n_{i}}=-\frac{P_{12}\left(a_{i}, n_{i}, X_{i}\right)}{P_{11}\left(a_{i}, n_{i}, X_{i}\right)}
$$

Under an assumption of diminishing returns to defensible space, the denominator in this equation is positive. The sign of the numerator depends on the relationship between own and others' defensible space. Shafran explains that $P_{12}<0$ implies strategic complementarities: the benefits of own defensible space increase as others increase their defensible space. Conversely, $P_{12}>0$ implies strategic substitutes. Shafran suggests that either of these relationships may be plausible in different empirical contexts. Complementarities could be present if "the reduction of fuel loads in the neighborhood of a house reduces the threat of crown fires reaching the house and therefore increases the effectiveness of defensible space as a protective measure" (p. 490). Meanwhile, the case of substitutes could arise when "fuel load reductions of neighbors [...] act as a buffer which reduces the likelihood of a wildfire reaching the property, thereby reducing the need for protective measures like defensible space" (p. 490). Shafran goes on to argue that, "If houses do not have immediate neighbors on all sides or if they are spaced sufficiently far apart that a significant threat will exist regardless of neighbors' actions, then a more compelling case can be made for strategic complementarities" (p. 490).

\subsection{Social norms}

To Shafran's basic model of risk externalities, we add a social norms function $S_{i}\left(a_{i}, n_{i}\right)$. This term imparts a reward or penalty based on the relationship between an individual's mitigation level $a_{i}$ and that of their neighbors $n_{i}$.

$$
U=y-c \cdot a_{i}-P\left(a_{i}, n_{i}, X_{i}\right) \cdot L+S_{i}\left(a_{i}, n_{i}\right)
$$

$S_{i}(\cdot)$ can be parameterized in multiple ways depending on the nature of the social norm effect. For example, Brock and Durlauf (2001) present one parameterization that they refer to as a "proportional spillovers" effect $S_{i}\left(a_{i} n_{i}\right)$, where the percentage change in utility from 
a change in neighbors' decisions is constant given the individual's choice, and a second "pure conformity effect" $-S_{i}\left(a_{i}-n_{i}\right)^{2}$ that penalizes mitigation behaviors that deviate from the average mitigation level among neighbors. For the purposes of this exposition, we assume that $S_{i}(\cdot)$ is heterogenous across individuals and generally has the property that it is everywhere increasing, $S_{i}^{\prime}\left(a_{i}, n_{i}\right)>0$, taking on negative values when $a_{i}<n_{i}$, positive values when $a_{i}>n_{i}$, and zero when $a_{i}=n_{i}$. Further, the marginal benefit of mitigating more than others decreases with distance above the norm, $S_{i}^{\prime \prime}\left(a_{i}, n_{i}\right)<0$ when $a_{i}>n_{i}$ and similarly the marginal penalty of mitigating less than others also decreases with distance below the norm, $S_{i}^{\prime \prime}\left(a_{i}, n_{i}\right)>0$ when $a_{i}<n_{i}$. As an example, the transformed logistic function, $S_{i}(x)=\alpha_{i}\left(\frac{e^{\beta_{i} x}}{1+e^{\beta_{i} x}}-0.5\right), \alpha_{i}>0, \beta_{i}>0$ satisfies these properties along with many other transformed differentiable s-shaped sigmoid functions.

Maximizing expected utility in the level of mitigation now yields the following first order condition:

$$
c=-P_{1}\left(a_{i}, n_{i}, X_{i}\right) \cdot L+S_{i}^{\prime}\left(a_{i}, n_{i}\right)
$$

Totally differentiating with $d c=0$ and rearranging tells us that the effect of a change in neighbors' defensible space on an agent's own mitigation level is now given by:

$$
\frac{d a_{i}}{d n_{i}}=\frac{-\left[P_{12}\left(a_{i}, n_{i}, X_{i}\right) \cdot L+S_{i}^{\prime \prime}\left(a_{i}, n_{i}\right)\right]}{\left[P_{11}\left(a_{i}, n_{i}, X_{i}\right) \cdot L-S_{i}^{\prime \prime}\left(a_{i}, n_{i}\right)\right]}
$$

Comparing this with the scenario without social norms (Eq. 4), we see that the total effect now depends on a) the sign of the risk interdependency effect $\left(P_{12}\left(a_{i}, n_{i}, X_{i}\right)\right)$, and b) the sign and magnitude of the social norms component, $S_{i}^{\prime \prime}\left(a_{i}, n_{i}\right)$. Specifically, to ensure the numerator is positive, we need both $P_{12}\left(a_{i}, n_{i}, X_{i}\right)<0$ and $S_{i}^{\prime \prime}\left(a_{i}, n_{i}\right)<0$. The latter occurs when $a_{i}>n_{i}$ which would also imply the denominator is positive since $P_{11}\left(a_{i}, n_{i}, X_{i}\right)>0$ and $S_{i}^{\prime \prime}\left(a_{i}, n_{i}\right)<0$. Therefore, the conditions for strategic complements in risk interdependency combined with individual mitigation above the norm give a clear prediction for $\frac{d a_{i}}{d n_{i}}>0$ in our model. These conditions intuitively reinforce each other. Complements in the pure sense of changing probabilities would encourage higher levels of individual mitigation making individual mitigation above the norm more likely.

Moving the other direction, are there any conditions to ensure $\frac{d a_{i}}{d n_{i}}<0$ ? $P_{12}\left(a_{i}, n_{i}, X_{i}\right)>0$ and $S_{i}^{\prime \prime}\left(a_{i}, n_{i}\right)>0$ will result in a negative numerator and imply $a_{i}<n_{i}$. However, $S_{i}^{\prime \prime}\left(a_{i}, n_{i}\right)>0$ when $a_{i}<n_{i}$ does not ensure a positive denominator to result in $\frac{d a_{i}}{d n_{i}}<0$. This could be accomplished with the additional condition $P_{11}\left(a_{i}, n_{i}, X_{i}\right) \cdot L>S_{i}^{\prime \prime}\left(a_{i}, n_{i}\right)$. Alternatively, suppose $P_{12}\left(a_{i}, n_{i}, X_{i}\right)>0$ and $a_{i}>n_{i}$ implying $S_{i}^{\prime \prime}\left(a_{i}, n_{i}\right)<0$. Then, if $P_{12}\left(a_{i}, n_{i}, X_{i}\right) \cdot L>-S_{i}^{\prime \prime}\left(a_{i}, n_{i}\right), \frac{d a_{i}}{d n_{i}}<0$. Both of these cases require that the respective rate of change for marginal losses exceed the rate of change for marginal utility of social norm distance. This analysis suggests that with social norms, a higher level of neighbors' mitigation $n_{i}$ could either increase or decrease individual mitigation $a_{i}$.

\section{Methods}

Drawing insights from this conceptual model and prior studies, we designed a choice experiment to measure the effects of risk interdependency and social norms on wildfire mitigation behaviors. Specifically, the design of our experiment takes advantage of the 
fact that neighbors' mitigation and fuel conditions factor into the risk interdependency and social norms pathways in two different ways. The risk interdependency effect operates through changes in wildfire risk levels that result from different fuel conditions on neighboring properties: dense vegetation translates to higher wildfire risk, while sparse vegetation means lower risk. In fact, this is true whether sparse vegetation came about naturally (e.g., through the lay of the land, naturally occurring vegetation types, or previous fires in the area) or through neighbors' mitigation actions. Meanwhile, social norms operate through neighbors' actions rather than their fuel conditions alone. We use this insight to build an experiment that addresses the following research questions and hypotheses:

Research Question 1 (Risk Interdependency) Do neighbors' vegetation levels affect homeowners' wildfire mitigation choices?

Hypothesis 1a (Strategic Complements) Having more neighbors with sparse vegetation will make homeowners more likely to take mitigation action on their own properties.

Hypothesis 1b (Strategic Substitutes) Having more neighbors with sparse vegetation will make homeowners less likely to take mitigation action on their own properties.

Research Question 2 (Social Norms) Do neighbors' mitigation actions affect homeowners' wildfire mitigation choices?

Hypothesis 2 Having more neighbors who have taken mitigation action will make homeowners more likely to take mitigation action on their own properties.

In this section, we describe our data collection and sampling strategy, our experimental design, and our data analysis methods.

\subsection{Data collection}

The choice experiment was implemented via a web-based survey of homeowners living in areas of wildfire risk in Colorado's Western Slope (i.e., the area of the state west of the Continental Divide.) The Western Slope was selected for this research for several reasons. First, a combination of factors is exacerbating wildfire risk in this area, including rapid amenity-migration-driven population growth, beetle epidemics, and weather and climate variability. However, considerably less research has been done in this area compared to the more densely population Front Range region. Second, like other fire-prone areas, communities across the Western Slope have been implementing policies and programs such as Firewise communities and Community Wildfire Protection Plans (CWPPs) that seek to harness the power of social norms to promote wildfire mitigation in the face of interdependent fire risk. Third, the Western Slope covers a diverse set of communities with varying ecological and socioeconomic characteristics. Within the "red zone" (Fig. 1), there is considerable variation in actual risk level due to variation in micro-climates, terrain, and other factors such as beetle infestations. Meanwhile, economic activity varies in this region: energy extraction, tourism, ranching, and fruit farming are leading activities.

We used several geospatial databases to construct our sample frame. First, we obtained parcel data from county tax assessor databases in 16 counties across the Western Slope and mapped all parcels in these counties. Parcel characteristics in these data include: year 


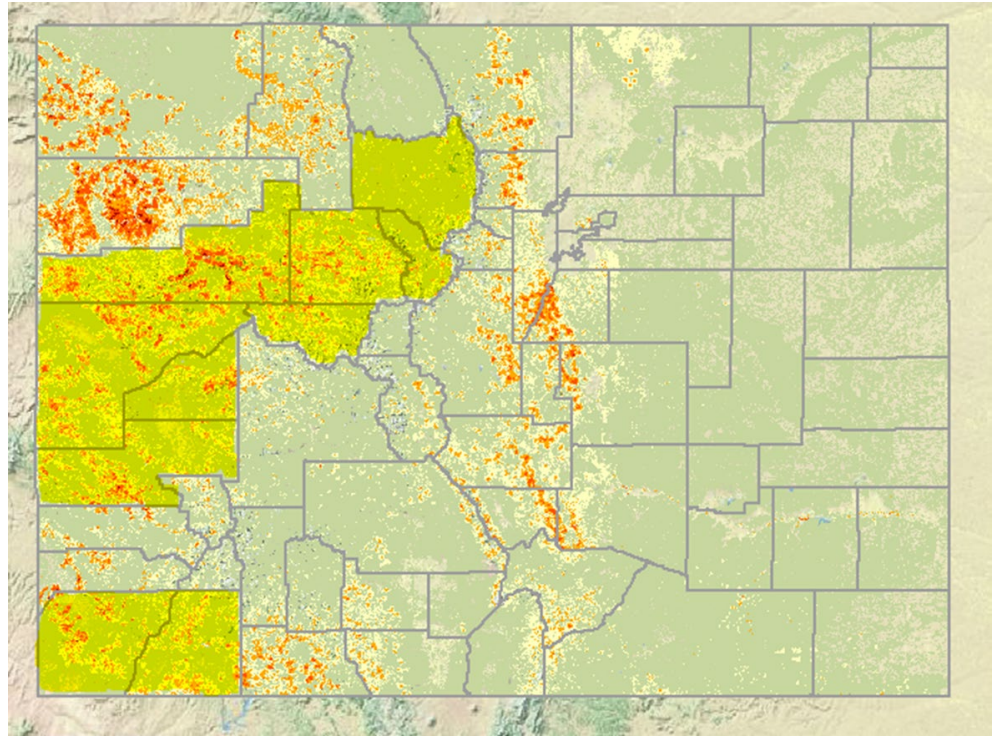

Fig. 1 Map of wildfire risk in Colorado. Study counties highlighted in yellow. Source: COWRAP

built, year of purchase, site address, subdivision name, zoning type, and mailing address. Second, data from the Colorado Wildfire Risk Assessment Portal (CSFS 2017) identifies areas designated as wildland-urban interface (WUI), categorizes these areas according to housing density, and provides a WUI risk index for each area. Third, in order to conduct our survey online, we needed to target areas with reasonably high levels of Internet coverage. FCC data were used to map Internet availability across the study area. Once this dataset was assembled, we generated the sample frame using the following eligibility criteria:

1. Residential zoning classification.

2. Owned by Colorado residents (determined by owner's mailing address, which did not always match the parcel's physical address).

3. Presence of housing structure on the property (determined by removing VACANT parcels and MOBILE homes, and missing "YEARBUILT" values).

4. WUI classification, with housing density greater than 1 house/40 acres (such that households' neighbors actions would have some relevance for their decisions).

5. WUI risk rating in the upper half of the CO-WRAP rating index scale.

6. At least 400/1000 homes with Internet access at no less than $768 \mathrm{kbps}$ (typical DSL-type dial-up connection).

The survey's target sample size was 1000 respondents. Based on prior work, we estimated that we would achieve a $25 \%$ response rate, such that 4000 households were recruited for the study. We retained the 10 largest counties (by total population) from the sample frame, and randomly selected recruits from each county in proportion to the county's population size. Following a lengthy pretesting phase, we determined that the most effective recruitment strategy involved mailing invitation letters to respondents with a $\$ 2$ bill as an incentive (Brenkert-Smith et al. 2018). The online survey's URL was printed on the letter. 
Reminder letters were sent to non-responders (tracked using ID codes used to log in to the survey) approximately one and two weeks after the initial mailing.

The survey was programmed using Qualtrics online survey software. A short initial section asked about the respondent's current WUI residence, including wildfire risk perceptions (probability that a fire will start on or spread to one's property in the next five years, and probability that home would be destroyed or severely damaged if a fire reached their property) and mitigation actions taken (reducing vegetation within 30 feet or beyond 30 feet of home, making structural improvements). The choice experiment section (described below) followed. After the experiment, additional questions collected information about: social interactions with and attitudes toward neighbors in their communities; wildfirerelated perceptions and attitudes; wildfire-related events in their communities; wildfire experiences; homeowners' insurance; risk attitudes; and socioeconomics.

\subsection{Experimental design}

Using the theoretical model outlined in the previous section, we designed a choice experiment in which respondents made mitigation decisions for their own (hypothetical) properties under varying conditions on neighboring properties. The choice experiment began by asking respondents to imagine that they had just moved to a new home on Colorado's Western Slope, and providing background information on their new community and home. Basic information on vegetation conditions and fire risk was also given: respondents were told that dense vegetation was related to higher wildfire risk. Different properties in the area could have dense or sparse vegetation, with sparse vegetation occurring two ways: (1) naturally sparse vegetation based on the lay of the land, naturally occurring types of plants, and previous wildfires that may have occurred and thinned the forest; and (2) mitigated properties, on which homeowners had taken action to reduce wildfire risk by doing things such as thinning trees and bushes and removing dead branches. The survey then explained that the respondent's new home was surrounded by four neighboring properties and that vegetation conditions on neighboring properties could fall into three possible states: dense, naturally sparse, or mitigated. The respondent's own property was divided into two zones, a near-home Zone 1 (less than 30 feet from the home), and Zone 2 (the rest of the property). This corresponds to the zone concept of wildfire risk reduction currently used by policy makers and practitioners to communicate different types of mitigation actions that homeowners should undertake (Cohen 2001, 2008). Zone 2 was always depicted as having dense vegetation; half of scenarios depicted Zone 1 as initially dense as well, while the other half showed Zone 1 as already having sparse vegetation (and thus not requiring further action).

After this introduction, the choice experiment began. Within each choice task, the respondent was shown a scenario depicting their property and the four surrounding properties. The respondent was then asked to indicate their perceived fire risk in that scenario: the perceived likelihood (on a 0 to 100 sliding scale) that a fire would start on or spread to their property in the next five years (probability), and the likelihood that if a fire reached their property, their home would be damaged or destroyed (consequences). (Note that these questions were asked in the same format as in the initial section, which measured risk perceptions for the respondent's real-world property.) Following these questions, the respondent was told that a mitigation company had visited their property and provided cost estimates for mitigation packages on each zone with dense vegetation. In half of scenarios, the respondent was told that a cost sharing program was available in their area and that the cost to them would be half of the total package cost. In addition, they were told that their 
local volunteer fire department had provided estimates of the amount of time it would take a fit adult to complete the actions involved in each package. These time costs did not vary across scenarios (i.e., the amount of time it would take to mitigate each zone was always the same, though these time costs varied between Zone 1 and Zone 2). The respondent was then asked what they would choose for each zone: purchasing the package, doing it themselves, or neither (leaving it alone). The resulting experimental attributes and their levels are shown in Fig. 2. The full factorial resulting from this design yielded 36 total scenarios ( 9 neighbor levels $\times 2$ own property levels $\times 2$ cost levels). These scenarios were split into 9 blocks, corresponding to the 9 different neighbor levels. For each respondent, the online

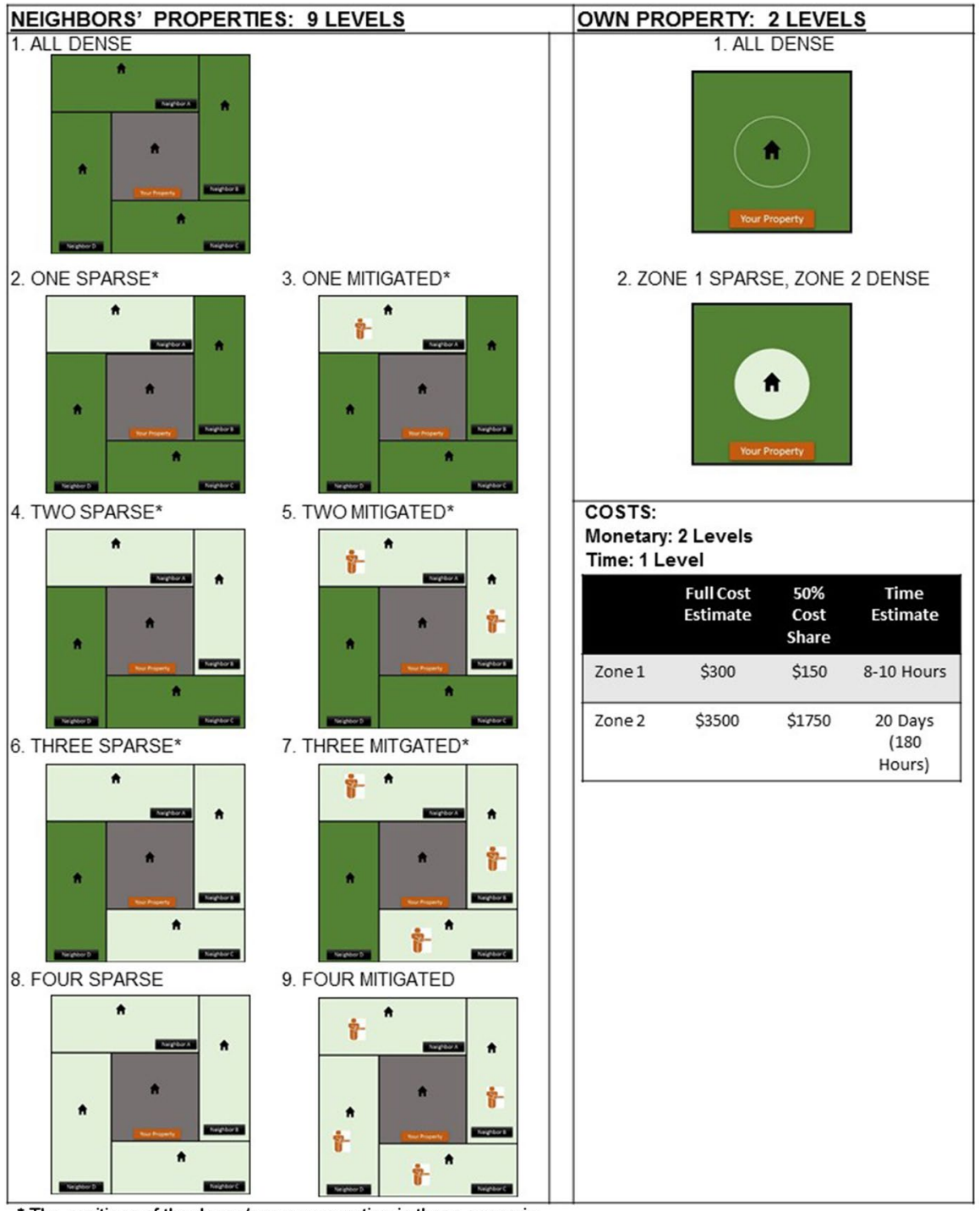

* The positions of the dense/sparse properties in these scenario were randomized across respondents.

Fig. 2 Experimental attributes and levels 
survey software (Qualtrics) selected a total of 8 scenarios by, first, randomly drawing 8 of the 9 blocks (neighbor levels) and then randomly drawing one scenario (combination of own property level and cost level) within each selected block. This ensured maximum variation in the key variable of interest, allowing us to assess how different neighbors' conditions influenced mitigation choices.

Debriefing questions were included following the choice experiment. Respondents indicated the importance of different factors (neighbors' vegetation density, whether neighbors had taken action, time and monetary costs, physical effort required to mitigate) when they were considering their mitigation choices. An open-ended question then asked respondents to give some reasons why neighbors' fuel conditions might affect their mitigation choice.

\subsection{Data analysis}

In each task, the respondent made a mitigation choice for each zone on their property that had initially dense vegetation, with the alternatives being (1) buy the mitigation package, (2) do it themselves, or (3) neither (leave zone as is). To analyze the resulting data, we use a random utility model in which utility is specified as a function of the ending state of vegetation on one's hypothetical property $\left(S_{j k}\right)$ and the monetary $\left(C_{j k}\right)$ and time $\left(T_{j k}\right)$ costs associated with the chosen alternative. Ending state is sparse $\left(S_{j k}=1\right)$ if either buy or do it yourself is chosen, and dense otherwise $\left(S_{j k}=0\right)$. Monetary cost is set to the total mitigation package costs if the buy option is chosen and zero otherwise; likewise, time costs are set to the total number of hours for completing the mitigation actions for the do it yourself option, and 0 for other alternatives. The total number of neighbors with sparse vegetation $\left(N S_{j}\right)$ and the number of neighbors that have mitigated $\left(N M_{j}\right)$ vary across scenarios (choice tasks), but not across alternatives within a choice task. (That is, neighbors' vegetation is the same no matter what action the respondent takes.) Thus, these variables must be interacted with alternative-specific attributes $\left(S_{j k}\right)$ in the random utility model given by:

$$
V_{i j k}=\beta_{0}+S_{j k} * \beta_{1}+C_{j k} * \beta_{2}+T_{j k} * \beta_{3}+\left(S_{j k} * N S_{j}\right) * \beta_{4}+\left(S_{j k} * N M_{j}\right) * \beta_{5}+\varepsilon_{i j k}
$$

where $i=$ individuals (respondents), $j=$ scenarios (choice tasks), and $k=$ alternatives (possible actions that can be chosen within a choice task). In this model, $\beta_{4}$ captures the risk interdependency effect, while $\beta_{5}$ measures the influence of social norms.

We estimate Eq. 8 using both conditional logit and mixed (random parameters) logit specifications. In addition, we examine whether risk interdependency and social norms effects vary with observable respondent characteristics by interacting covariates with these terms.

\section{Results}

\subsection{Sample characteristics}

Table 1 summarizes our survey response rates by county. We show both the total number of responses that were initiated in the online survey and the number of completed responses. The lowest completed response rate (12.8\%) was for Montrose county, likely due to the fact that the tax assessor database for this county did not include property owner names so that recruitment letters had to be addressed generically to "Current Montrose County 
Resident." In the other nine counties, response rates ranged from 23.8\% (Montezuma) to $35.7 \%$ (Grand).

Characteristics of survey respondents are summarized in Table 2. On average, respondents were in their late 50s, and a little over a third of respondents were retired. About $60 \%$ of respondents were male; invitation letters were addressed to the property owner or owners listed in the tax assessor's databases and did not specify which household member should complete the survey. (In some instances, respondents wrote in that they completed the surveys jointly as a couple.) Education levels in the sample were quite high, with about $80 \%$ of respondents having a college degree or higher.

Prior to the choice experiment, we asked respondents to indicate, on a scale from 0 to 100 , their perceived likelihood that a wildfire would start on or spread to their own property within the next 5 years. Perceived risks were fairly high; mean probability was $17 \%$ (median $=10 \%$ ) with a range from 0 to $96 \%$. When asked (also before the choice experiment) about mitigation actions respondents had taken on their own properties, about $56 \%$ said they had taken action to reduce vegetation in the zone within 30 feet of their home, and about $35 \%$ said they had taken action in the zone more than 30 feet from their home. In response to Likert scale questions after the experiment, about $57 \%$ of respondents agreed or strongly agreed with the statement, "I spend a lot of time on home improvements."

About a quarter of respondents said that neighbors' opinions influenced their actual wildfire mitigation decisions "Quite a bit" or "A lot." Another set of Likert scale questions asked respondents about their risk-taking habits in various domains. A small proportion of respondents (about 6\%) agreed or strongly agreed with the statement "I am a daredevil," while about $17 \%$ indicated some level of agreement with the statement, "I am not afraid to take risks with my money," and nearly a quarter of respondents either disagreed or strongly disagreed with the statement, "I avoid any activities that could be harmful to my health." We are interested in assessing whether these risk attitudes are related to respondents' mitigation choices, and their responses to social effects, in the choice tasks.

Table 1 Response rates by county

\begin{tabular}{llcllll}
\hline County & Total delivered & Responses & $\begin{array}{l}\text { Response } \\
\text { rate }(\%)\end{array}$ & $\begin{array}{l}\text { Completed } \\
\text { response rate } \\
(\%)\end{array}$ & $\begin{array}{l}\text { \% Com- } \\
\text { pleted } \\
\text { sample }\end{array}$ & \% Eligible parcels \\
\hline Delta & 250 & 89 & 35.6 & 25.6 & 6.7 & 9.8 \\
Eagle & 334 & 109 & 32.6 & 25.1 & 8.8 & 8.4 \\
Garfield & 380 & 132 & 34.7 & 27.4 & 10.8 & 9.7 \\
La Plata & 405 & 148 & 36.5 & 30.1 & 12.7 & 10.5 \\
Mesa & 1144 & 332 & 29.0 & 24.1 & 28.8 & 30.4 \\
Montrose & 494 & 96 & 19.4 & 12.8 & 6.6 & 13.1 \\
Pitkin & 117 & 36 & 30.8 & 23.9 & 2.9 & 2.7 \\
Grand & 143 & 72 & 50.3 & 35.7 & 5.3 & 4.0 \\
Summit & 208 & 77 & 37.0 & 31.3 & 6.8 & 6.0 \\
Montezuma & 193 & 56 & 29.0 & 23.8 & 4.8 & 5.2 \\
No ID & - & 137 & - & - & 5.8 & - \\
Total & 3668 & 1284 & 35.0 & 26.1 & 100.0 & 100.0 \\
\hline
\end{tabular}

a Owner names not available: letters addressed to "Current Montrose County Resident" 
Table 2 Summary statistics

\begin{tabular}{lccccc}
\hline Variable & $N$ & Mean & SD & Min. & Max. \\
\hline Age & 802 & 57.34 & 12.54 & 26 & 92 \\
Female & 827 & 0.380 & 0.486 & 0 & 1 \\
High school dropout & 858 & 0.007 & 0.083 & 0 & 1 \\
High school graduate & 858 & 0.072 & 0.259 & 0 & 1 \\
Some college & 858 & 0.146 & 0.353 & 0 & 1 \\
College degree & 858 & 0.385 & 0.487 & 0 & 1 \\
Postgraduate work & 858 & 0.366 & 0.482 & 0 & 1 \\
Advanced degree & 858 & 0.354 & 0.479 & 0 & 1 \\
Retired & 833 & 0.359 & 0.48 & 0 & 1 \\
Perceived probability that a wildfire will start or & 811 & 17.29 & 17.92 & 0 & 96 \\
$\quad$ spread to their property in the next 5 years & & & & & 1 \\
Has reduced vegetation within 30' of own home & 857 & 0.557 & 0.497 & 0 & \\
Has reduced vegetation beyond 30' of own home & 857 & 0.354 & 0.478 & 0 & 1 \\
Spends a lot of time on home improvements & 836 & 0.574 & 0.495 & 0 & 1 \\
Neighbors' opinions influence mitigation & 858 & 0.259 & 0.438 & 0 & 1 \\
Considers themselves a daredevil & 834 & 0.062 & 0.242 & 0 & 1 \\
Not afraid to take risks with money & 833 & 0.168 & 0.374 & 0 & 1 \\
Avoids activities harmful to health & 837 & 0.247 & 0.432 & 0 & 1 \\
\hline
\end{tabular}

\subsection{Choice experiment results}

\subsubsection{Effects of neighbors' conditions on risk perceptions}

Conceptually, our model posits that the risk interdependency effect operates through respondents' risk perceptions. That is, changes in fuel conditions on neighbors' properties influence the respondent's perceived risk that they will experience a fire, thereby influencing the perceived efficacy of their own mitigation and shaping the respondent's mitigation choice. As a part of each choice task, respondents reported on their wildfire risk perceptions given that particular scenario. As a first test of whether the experimental design led respondents to perceive a shared wildfire risk, Table 3 shows how respondents' subjective probability that a fire would start on or spread to their experimental property in the next five years varies with the total number of sparse neighbors and whether or not those sparse neighbors had mitigated. In these regressions, we control for respondent-specific variation in risk perceptions in two different ways. The first column includes a control for the subjective probability of fire that the respondent provided for their actual, real-world property prior to the choice experiment. In the second column, we include respondent fixed effects. In both models, the coefficient on the number of sparse neighbors is negative and statistically significant at the 0.001 level. Having one more sparse neighbor decreases the perceived risk of fire by about 8 percentage points, and going from 0 to 4 sparse neighbors decreases perceived fire risk by 32 percentage points. Meanwhile, the insignificant coefficient on the "mitigated sparse" neighbors term indicates that respondents did not perceive a differential effect on fire risk from having mitigated versus naturally sparse neighbors, validating our experimental design. (Recall that our intention was for risk interdependency 
to operate through the total number of sparse neighbors, regardless of whether they were naturally sparse or mitigated.)

On its own, however, this result does not tell us whether respondents perceived others' actions as strategic substitutes or complements to their own action. This depends not on how risk perception changes with others' conditions, but how the perceived marginal benefit of one's own mitigation changes at different levels of neighbors' fuel conditions. For this, we turn to respondents' mitigation choices.

\subsubsection{Choice frequencies and respondents' "switching" behavior}

Within each choice task, respondents chose whether to purchase a mitigation package (henceforth denoted BUY), do the mitigation themselves (DIY), or NEITHER, for each zone on their property that had dense vegetation (Zone 1 in about half of all choice tasks, Zone 2 for all tasks). In total, 949 unique respondents made a total of 3480 valid nonmissing choice selections for Zone 1, and 1001 respondents made a total of 7172 Zone 2 choices. Examining raw data on choice frequencies reveals a strong tendency of respondents to choose the two mitigation options (BUY and DIY) over the NEITHER option. This is particularly true for Zone 1: NEITHER was chosen in less than $5 \%$ of tasks, while BUY was chosen in $43 \%$ of tasks and DIY was chosen in the remaining $54 \%$ of tasks. The proportion choosing NEITHER is about twice as high in Zone 2 tasks, but this share is still just under $11 \%$, while BUY and DIY shares are $42 \%$ and $48 \%$, respectively.

Table 3 Risk perceptions

\begin{tabular}{lll}
\hline Variable & $\begin{array}{l}\text { Dependent variable is } \\
\text { respondent's perceived } \\
\text { probability that wildfire } \\
\text { will spread to their } \\
\text { experimental property }\end{array}$ \\
\cline { 2 - 3 } & $(1)$ & $(2)$ \\
\hline Total number of sparse neighbors & $-8.32^{* * *}$ & $-8.23^{* * *}$ \\
Number of mitigated sparse neighbors & $(0)$ & $(0)$ \\
Respondent's perception of wildfire risk & -0.14 & -0.20 \\
for their own property & $(0.50)$ & $(0.11)$ \\
Respondent fixed effects & $0.37^{* * *}(0)$ & - \\
Observations & No & Yes \\
$R^{2}$ & 6237 & 6588 \\
\hline
\end{tabular}

Coefficients are estimated by ordinary least squares

Standard errors, in parentheses, are clustered at the respondent level

In both columns, the perceived probability that wildfire will spread to their experimental property (the dependent variable) is measured as a percentage

$* * * p<0.01 ; * * p<0.05 ; * p<0.1$ 
Building on these raw frequencies, Table 4 shows within-respondent choice patterns to assess whether and how respondents varied their choices across tasks. To make meaningful within-respondent comparisons, for these panels we limit the analysis to respondents who completed a minimum number of tasks for each zone: 3 (out of a possible 4) tasks in Zone 1, and 6 (out of a possible 8) tasks for Zone 2. Data show that many respondents did not alter their behavior across the eight choice tasks that they faced. This is particularly true for Zone 1: 80\% of respondents always chose the same option in the tasks that involved a Zone 1 mitigation choice. The majority of respondents always chose a mitigation option; $33 \%$ always chose BUY, while $43 \%$ always selected DIY. Only 3\% of respondents always chose NEITHER for Zone 1 . For the $20 \%$ of respondents that did vary their Zone 1 choice, the majority (17\% of all respondents) switched between the two mitigation options (BUY/ DIY). In total, only $6 \%$ of respondents ever chose NEITHER for Zone 1.

The proportion of "never switchers" is lower in Zone 2, but still comprises more than half of the sample (58\% of the 876 respondents that completed at least 6 Zone 2 tasks). As in Zone 1, most of these respondents consistently chose a mitigation option (24\% BUY, $32 \%$ DIY), while only $3 \%$ of these respondents always chose NEITHER. Looking at this another way, we see that almost $80 \%$ of respondents always choose one of the two mitigation options. In total, just over a fifth of respondents ever chose NEITHER for Zone 2.

We also examined whether or not "switchers" differed from "never switchers" according to the observable respondent characteristics in Table 2. Respondents who always selected the same option in Zone 2 in the choice tasks ("never switchers") were slightly older on average than those who altered their choices; the difference is statistically significant at the $5 \%$ level but substantively small (58 years vs 56 years). "Never switchers" were also somewhat more likely to report that they had actually engaged in mitigation in Zone 2 on their "real-world" properties. This type of mitigation was reported by $38 \%$ of "never switchers" compared to $32 \%$ of "switchers" ( $p=0.09$ ). No other notable differences in observable characteristics were found between these respondents.

Table 4 Respondents' choice behavior

\begin{tabular}{lllll}
\hline Never Switchers & \multicolumn{3}{l}{} & \\
\hline & Always BUY & Always DIY & Always NEITHER & $\begin{array}{l}\text { Total Never } \\
\text { Switchers }\end{array}$ \\
\hline Zone 1 & & & 653 \\
& 277 & 359 & 17 & $80 \%$ \\
Zone 2 & $34 \%$ & $44 \%$ & $2 \%$ & 467 \\
& 189 & 255 & 23 & $57 \%$ \\
\hline
\end{tabular}

Switchers

BUY/DIY BUY/NEITHER DIY/NEITHER BUY/DIY/NEI- Total Switchers
THER

\begin{tabular}{llllll}
\hline Zone 1 & 144 & 5 & 7 & 11 & 167 \\
& $18 \%$ & $1 \%$ & $1 \%$ & 15 & $20 \%$ \\
Zone 2 & 191 & 68 & 39 & 55 & 353 \\
& $23 \%$ & $8 \%$ & $5 \%$ & $7 \%$ & $43 \%$ \\
\hline
\end{tabular}

In each panel, the first row is the number of respondents and the second row is the percentage of all respondents 
Taken together, these results indicate that most respondents preferred the mitigation options for Zones 1 and 2 in the choice tasks. These high stated preferences for mitigation are certainly explained in part by the hypothetical nature of the experiment; for example, while about $93 \%$ of respondents indicated that they would always chose to mitigate in Zone 1 , the proportion reporting that they had taken action to reduce vegetation in this zone on their actual property was only $55 \%$; in Zone $2,77 \%$ consistently chose to mitigate in the experiment, while only $34 \%$ reported "real-world" Zone 2 mitigation actions. It may also be the case that the time and monetary costs of mitigation that we presented in the survey were lower than perceived costs on one's actual properties. (While our cost figures were developed in consultation with wildfire mitigation contacts in the study area to be realistic for the hypothetical scenario we presented, actual costs would vary depending on property size and characteristics.) In the end, our interest here is not in assessing absolute willingness to engage in mitigation action (or willingness to pay), but rather to assess whether and how choices vary as a function of neighbors' actions. Given the overall lack of variation in Zone 1 choices, and the smaller number of these choices, subsequent analyses focus primarily on identifying social effects for Zone 2 choices.

\subsubsection{Estimates of social effects}

To analyze respondents' choice behavior, we estimate models in which the dependent variable is an indicator for whether or not a particular alternative was selected in a given choice task. Alternatives are defined as the combination of Zone 1 and Zone 2 actions that can be chosen within a given task. In total, there are 12 possible alternatives for any given task, produced as a combination of the three options that are always present for Zone 2 (\{BUY, DIY, NEITHER \}), and four possible options for Zone 1 (\{BUY, DIY, NEITHER \} for tasks with Zone 1 initially dense and $\{\mathrm{NA}\}$ for tasks where Zone 1 is presented as initially sparse). The dependent variable thus records which of these 12 options was selected for each task. Alternative-specific attributes include indicators for whether the selected action results in the ending state of each zone being sparse, and the total monetary and time costs of the selected alternative (equal to the sum of incurred Zone 1 and Zone 2 costs). The social effects of interest are estimated by interacting neighbors' characteristics (which vary across tasks but not across alternatives) with the "Zone 2 sparse" indicator. To measure risk interdependency effects, we use a continuous measure of the number of neighbors with sparse vegetation (natural or mitigated). This interaction term thus measures how respondents' likelihood of choosing a mitigation option for Zone 2 changes as the number of sparse neighbors increases. To measure the effect of social norms, we include an interaction with an indicator variable for whether or not a majority ( 3 or 4 ) of neighbors had engaged in mitigation action. The coefficient on this interaction term thus captures the change in likelihood of choosing mitigation in scenarios where a majority of neighbors have mitigated, compared to scenarios in which a majority of neighbors have not mitigated. Alternative specifications for both of these social effect interactions were explored, including using continuous measures for both sparse neighbors and mitigated neighbors; qualitative results did not differ substantially from what is reported here.

Table 5 presents model results estimated using conditional and mixed logit specifications. We estimate these models on the full sample (all respondents, all completed choice tasks), and on two restricted samples that include only those respondents that completed multiple choice tasks and (1) had any variation in Zone 2 choices across tasks ("Total Switchers" in the bottom panel of Table 4), or (2) switched between no mitigation 
("Neither") and a mitigation option ("Buy" or "DIY") across tasks. The top panel of Table 5 provides the two social effect estimates, corresponding to $\beta_{4}$ (risk interdependency) and $\beta_{5}$ (social norms) in Eqn. 8. Across the conditional logit models, the risk interdependency effect is negative and statistically significant at the 0.001 level, indicating that respondents were less likely to choose to mitigate as the share of their neighbors with sparse vegetation increased. In the mixed logit models, the risk interdependency coefficient is still negative, but is only statistically significant in the sample that is limited to respondents that switched between mitigation and non-mitigation options across choice tasks. The statistically significant standard deviations on risk interdependency coefficient estimates from the mixed logits indicate that there is heterogeneity across respondents in their choice behavior. For the social norms effect, point estimates are positive in all but one model (mixed logit for mitigation/non-mitigation switchers), with none of the effects being statistically significant at the 0.10 level. That is, we do not observe a differential effect of mitigated vs naturally sparse neighbors, and on average social norms effects do not appear to be counteracting the negative risk interdependency effect to induce higher mitigation levels.

Other experimental attributes, whose coefficients are shown in the bottom panel of the table, have the expected signs. Both time and monetary costs of mitigation have negative effects. (The ratio of these coefficients corresponds to a value of time of $\$ 12.75$ per hour, perhaps reasonable for work around the house.) All else equal, respondents prefer to choose mitigation for both Zone 1 and Zone 2 .

\subsubsection{Heterogeneity in social effects by respondent characteristics}

To probe heterogeneity further, we re-estimated Eq. 8 with the addition of interactions with binary respondent covariates:

$$
\begin{aligned}
V_{i j k}= & \beta_{0}+S_{j k} * \beta_{1}+C_{j k} * \beta_{2}+T_{j k} * \beta_{3}+\left(S_{j k} * N S_{j}\right) * \beta_{4}+\left(S_{j k} * N M_{j}\right) * \beta_{5} \\
& +\left(S_{j k} * N S_{j} * R_{i}\right) * \beta_{6}+\left(S_{j k} * N M_{j} * R_{i}\right) * \beta_{7}+\left(S_{j k} * R_{i}\right) * \beta_{8}+\varepsilon_{i j k}
\end{aligned}
$$

where $R_{i}$ is some characteristic for respondent $i$. Specifically, we report interactions with indicators for whether or not the respondent: (1) identified as female; (2) reported conducting "Zone 2" mitigation (more than 30 feet from their home) on their actual property, (3) agreed or strongly agreed that they spent a lot of time on home improvements; (4) said neighbors' opinions influenced their mitigation decisions "Quite a bit" or "A lot," (5) agreed or strongly agreed that they were a "daredevil"; and (6) agreed or strongly agreed that they were not afraid to take risks with their money. Models were run separately for each of these interaction variables, and each covariate was interacted with three of the terms included in the base model. First, we interacted the covariate with the indicator for whether the selected package resulted in Zone 2 being mitigated. The coefficient on this interaction term tells us if respondents in the category indicated by the covariate (e.g., females) were more likely to select a mitigation package than respondents in the reference category (e.g., males). Second, we also included an interaction between the covariate and the "risk interdependency" term (number of sparse neighbors $\times$ Zone 2 mitigation). Continuing with the gender example, this coefficient tells us if females respond differently than males to neighbors' fuel conditions. Finally, we include a similar interaction with the "social norms" term (more than 2 mitigated neighbors $\times$ Zone 2 mitigation). This coefficient would tell us whether females' responses to neighbors' actions differ from males. Results are presented in Table 6. The first column replicates column (1) in Table 5, without 
additional interaction terms, while columns (2)-(7) each include interactions with a different covariate.

We find that female respondents were somewhat less likely than males to choose a mitigation package (negative and marginally significant coefficient on the female $\times$ Zone 2 cleared term). Respondents who reported that they had actually taken action to reduce vegetation on their properties (in a survey question posed prior to the choice experiment) were more likely to choose a mitigation package. However, we also find that the interaction between this covariate and the risk interdependency term is negative and significant, indicating that these "real-life mitigators" were even more likely than non-mitigators to reduce their mitigation in scenarios where more neighbors had sparse vegetation. We also find high levels of mitigation among respondents who indicated that they spent a lot of time on general home improvement projects, though the interactions between this variable and the neighbors' condition variables are not significant.

Similarly, respondents who said their neighbors' opinions were important to their mitigation choice were more likely to choose a mitigation option for Zone 2, but did not differ in their reactions to neighbors' fuel conditions or mitigation actions. We examined interactions with the risk attitude indicators described in Table 2. Respondents that considered themselves "daredevils" were less likely to choose mitigation in Zone 2 . To a lesser extent, those who indicated monetary risk taking were also less likely to choose mitigation in the experiment. Neither of these risk attitudes significantly altered the social effects (risk interdependency or social norms).

We also examined interactions with other respondent covariates shown in Table 2: age, education, retirement status, risk perceptions, and health risk taking. None of these variables showed significant interactions with mitigation choices or social effects (not shown).

\section{Discussion}

Prior research on interdependent wildfire risk decisions has largely focused on the risk interdependency pathway: how do neighbors' fuel conditions and risk levels affect the perceived efficacy of one's own action, and thus one's mitigation decisions? While Shafran's original theoretical model posited that risk interdependency effects could be either positive (strategic complementarity) or negative (strategic substitution), empirical evidence from observational studies pointed toward positive social effects (Shafran 2008; Taylor 2015; Warziniack et al. 2019). This was interpreted as evidence that wildfire mitigation was characterized by strategic complementarities, and subsequent work has operated under the assumption of complementarity in examining equilibrium selection under different circumstances (Shafran 2010; Kroll and Shafran 2017). However, a key contribution of our paper is to acknowledge the possibility for a second social effect pathway, social norms, which also has the potential to generate positive social effects. Even if social norms had been acknowledged in the prior studies, their observational nature would have made it difficult, if not impossible, to disentangle risk interdependency and social norms effects. Our experimental study was designed to do just that. In this experiment, we found that risk interdependency effects were negative, while social norm effects were not apparent. The net effect was thus negative: having more neighbors with sparse vegetation made respondents less likely to choose mitigation. 


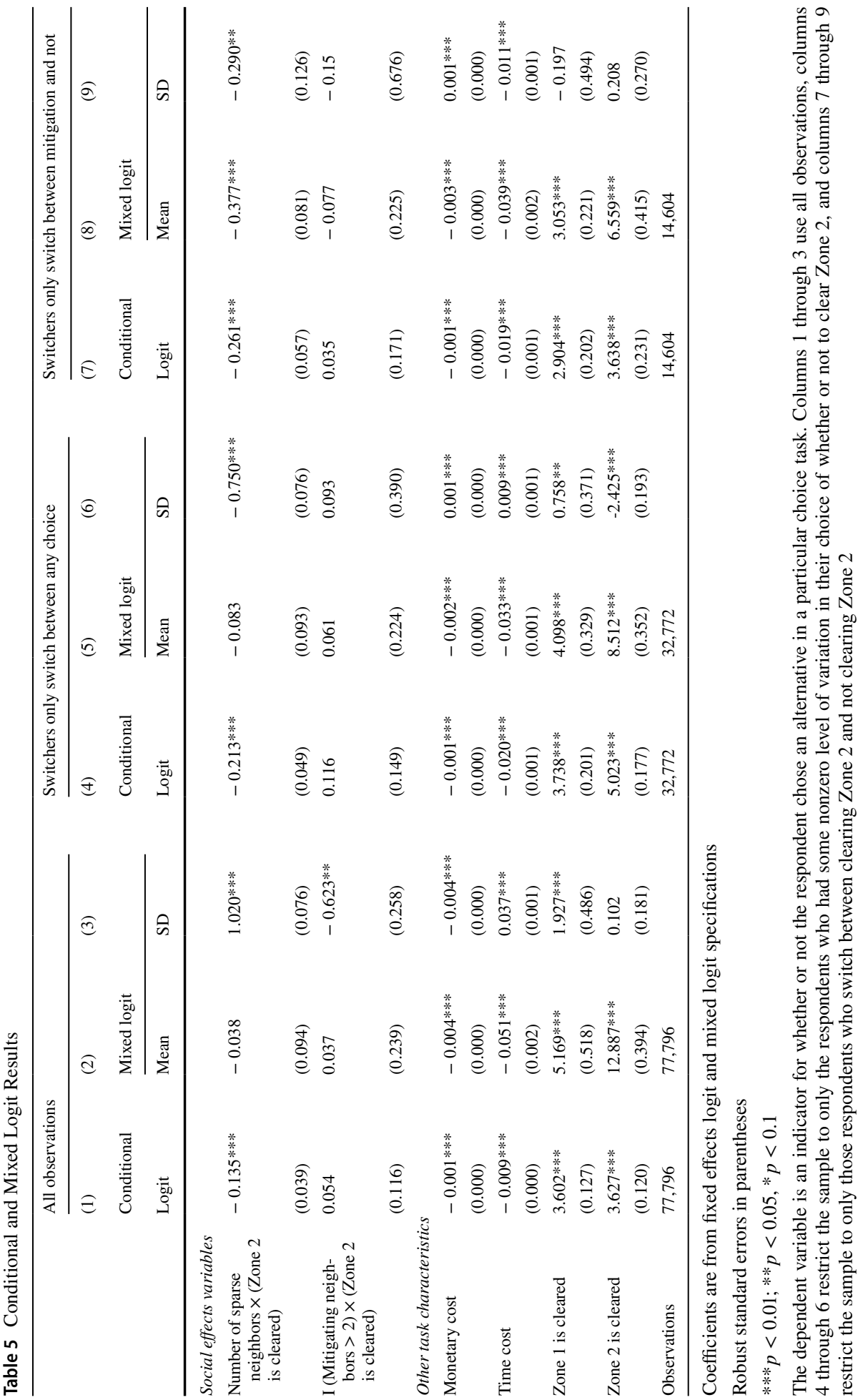




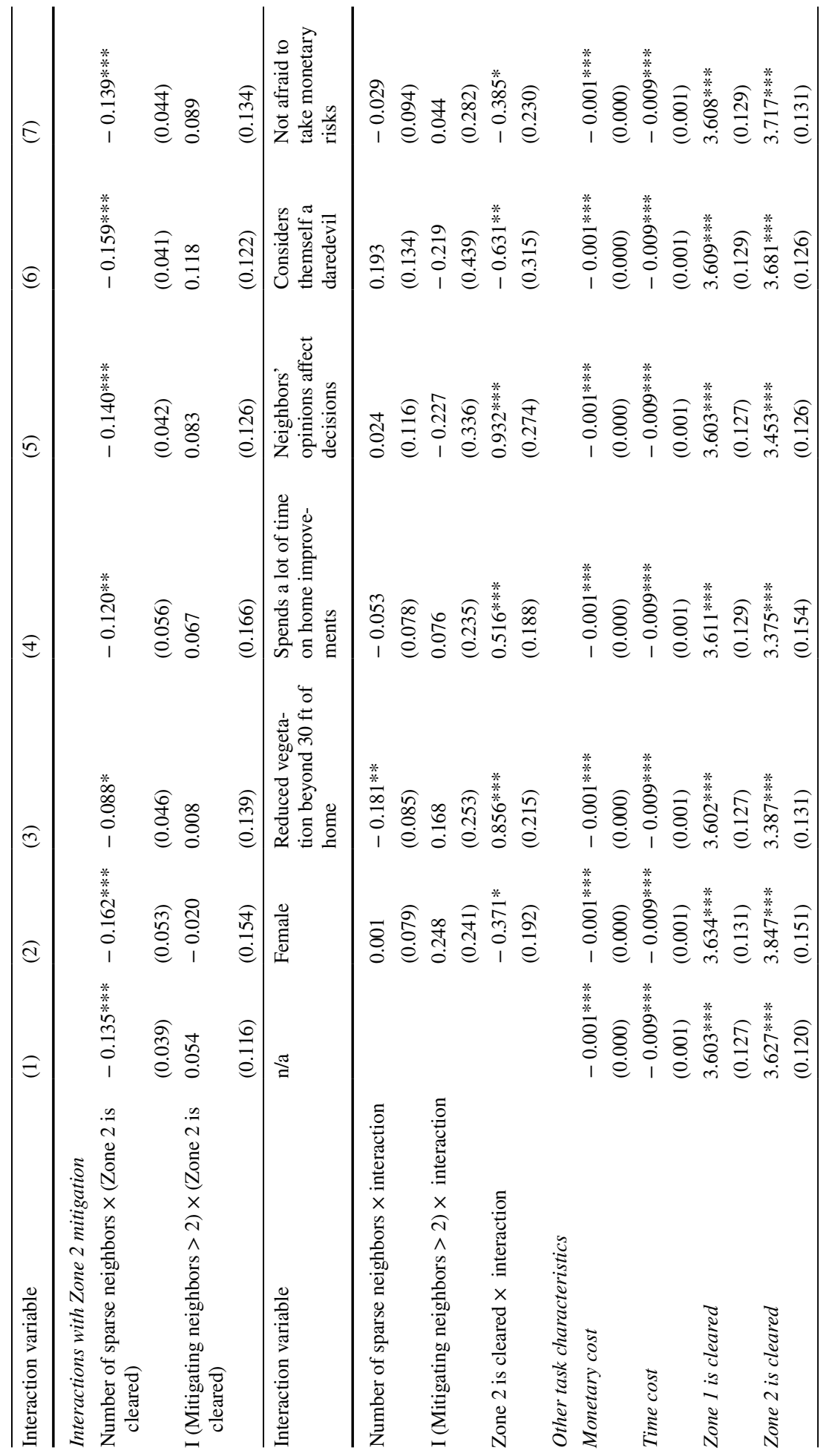




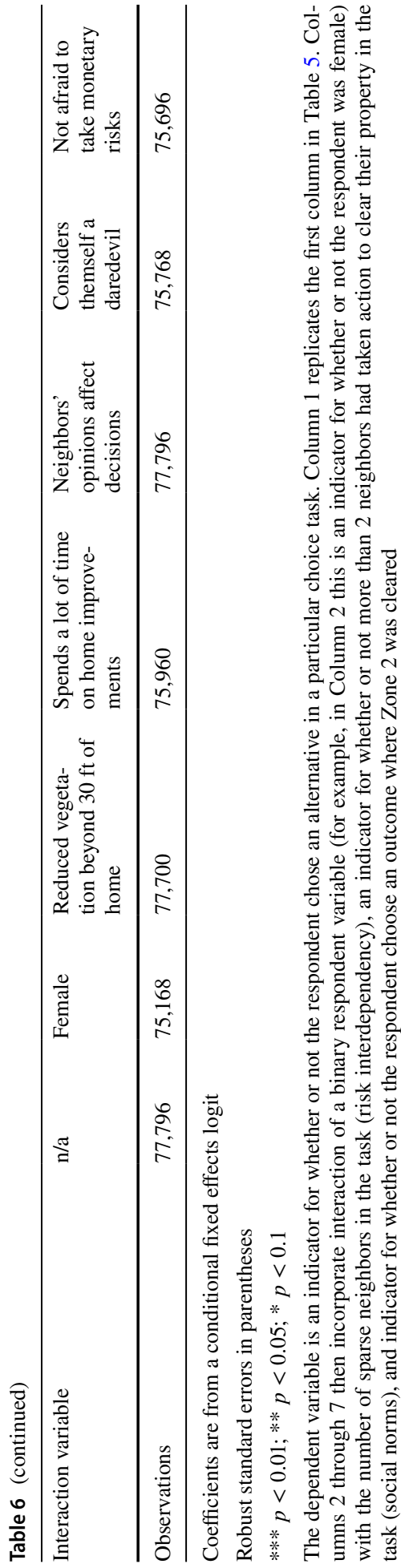


While we find no statistical evidence of social norms in the narrow context created in our experiments, it is important to recognize that contexts observed in the field can easily confound the measurement of risk interactions with influences from social norms. Let us return to our theoretical model and its conclusion that the net effect of a change in neighbors' conditions may result in higher or lower individual mitigation depending on the sign and magnitude of the two social effects. Figure 3 provides a simple diagram to illustrate this point. Oversimplifying, we present two possible states of the world regarding both risk interdependency and social norms. Risk interdependency can either exhibit strategic complementarity or substitution. As noted previously, this may depend on factors such as landscape type and housing density. Meanwhile, social norms may be present or absent (or, more realistically, vary in strength) based on factors such as community age and socioeconomic composition, proportion of full vs part time residents, and community members' worldviews. This two-by-two matrix generates four different possible community types. Now imagine a policy that enters each of these communities and exogenously changes the behavior of some agents, perhaps by conducting a lottery to allocate mitigation subsidies to a subset of community members. The question is how the neighbors of those lottery winners will respond: will they be more or less likely to mitigate on their own properties? In communities characterized by strategic complementarity (Quadrants I and II), we would expect positive social effects, with these effects being larger when social norms are present as well (Quadrant II). In communities where risk interdependency exhibits strategic substitution, however, the net effect depends on the presence and strength of social norms. Where social norms are absent or weak, we would expect to observe negative social effects: less mitigation action among neighbors of lottery winners (Quadrant IV). However, where social norms are strong, they may be able to overcome the negative substitution effect and lead to net positive social effects (Quadrant III).

According to this schematic, the conditions in our experiment appear to have created a Quadrant IV-type community. Without additional information, we cannot determine which of the three remaining quadrants best describes the communities where net positive social effects were observed in prior studies. However, we highlight some key differences between our experimental world and the contexts of these observational studies that may account for our differing results.

First, it is quite possible that risk interdependency effects are more likely to exhibit complementarities in the contexts Shafran and others have examined, rather than the

\begin{tabular}{|c|c|c|c|}
\hline & & \multicolumn{2}{|c|}{ Social Norms } \\
\hline & & Present & Absent \\
\hline \multirow{2}{*}{$\begin{array}{l}\text { Risk } \\
\text { Interdependency }\end{array}$} & Complementarity & $\begin{array}{c}\text { I } \\
\text { Positive } \\
\text { (Stronger) }\end{array}$ & $\begin{array}{c}\text { II } \\
\text { Positive } \\
\text { (Weaker) }\end{array}$ \\
\hline & Substitution & $\begin{array}{c}\text { III } \\
\text { Unclear } \\
\text { (depends on relative strength } \\
\text { of effects) }\end{array}$ & $\begin{array}{c}\text { IV } \\
\text { Negative }\end{array}$ \\
\hline
\end{tabular}

Fig. 3 Risk interdependency-social norms schematic. Schematic depicting different community types defined by risk interdependency (complementarity or substitution) and social norms (present or absent). Net effects are shown in each quadrant (positive, negative, or unclear) 
substitution effects we observe, due to their geographical characteristics. For example, Shafran's exposition of risk interdependency posits that homeowners are more likely to see neighbors' actions as strategic complements for their own mitigation in contexts where households are more spread apart and do not neighbor others on all sides, and that this describes his Boulder County sample relatively well. Similarly, Warziniack et al. (2019) find evidence of a positive spatial correlation in mitigation in a sample of Southwestern Colorado parcels that includes large homes on large properties. In contrast, our experimental neighborhoods were clearly set up to depict a different type of neighborhood, with relatively small lot sizes and close neighbors on all sides, a setting in which Shafran's description of a substitution relationship may be more apt since neighbors' mitigation may "act as a buffer which reduces the likelihood of a wildfire reaching the property" [Shafran, p. 490].

In addition to differences in the structure of risk interdependency between our experimental neighborhood and those examined in prior observational studies, we think it is quite likely that social norms are substantially stronger and more impactful in real-world settings than they were in our experiment. Some prior work has shown that people tend to underestimate the effect that norms exert on behavior in stated preference studies (Pronin et al. 2007; Schultz et al. 2007), and a number of recent field experiments have shown that social comparisons can influence a range of behaviors (Goldstein et al. 2008; Allcott 2011; Ferraro and Price 2013). Our experiment's key design element involved creating a contained, manipulable world where we could vary neighbors' conditions and observe the effect on respondent's choices. Thus, our experimental design allows us to do something-separating risk interdependency from social norms - that prior observational studies could not. However, the shift from a real-world setting to our experimental world also implied a shift and narrowing of the nature and types of social norms that were present in the decisionmaking environment. What we were ultimately able to show is that simply knowing that their (nameless, faceless) neighbors had taken action was not enough to push respondents to do more themselves. This was a test of a fairly simple descriptive norm, which tells a member of a group what most others in the group are doing (Cialdini et al. 1991), and in this case, these norms had little effect.

Building on this work, future studies should continue to work toward uncovering the pathways through which social effects operate, and teasing apart the effects of risk interdependency and social norms. This could be accomplished in part through richer experimental contexts that more closely mimic real-world settings (e.g., including face to face interactions in laboratory experiments, including both descriptive and injunctive norms messages (Cialdini et al. 1991), or using richer visual depictions of mitigated landscapes which may influence acceptability (Peterson and Vaske 2016). In addition, observational studies can attempt to measure the effects of both risk interdependency and social norms by incorporating social network analyses (to assess the effects of peers who may not be physical neighbors, for example) and by measuring respondents' attitudes toward mitigation. More broadly, incorporating other potential social effect pathways such as information sharing and learning will also be important for more fully understanding how the social context shapes risk mitigation choices in the face of wildfire hazards.

Understanding these effects is more than an academic exercise and may have implications for the types of policies that could effectively encourage more homeowners to take action to mitigate their wildfire risk. Returning to Fig. 3, knowing which quadrant a particular community falls into can help decision makers understand the potential opportunities and barriers to action. Crucially, policy "multiplier effects" may emerge in certain communities where strategic complementarities and/or strong social norms are present. In these areas, policies that encourage mitigation among a subset of community members 
(e.g., opinion leaders or a random subset of homes in an area) can result in other individuals following suit. In areas that exhibit strategic substitution, however, net effects will depend on whether social norms generate positive effects strong enough to overcome negative risk interdependency effects. The extent to which different real-world communities can be characterized according to this typology and the effectiveness of different policies across contexts are directions for future work.

Acknowledgements This material is based upon work supported by the National Science Foundation under Grant No. SES 1259448. Any opinions, findings, and conclusions or recommendations expressed in this material are those of the authors and do not necessarily reflect the views of the National Science Foundation. The authors have no conflicts of interest to declare.

Open Access This article is licensed under a Creative Commons Attribution 4.0 International License, which permits use, sharing, adaptation, distribution and reproduction in any medium or format, as long as you give appropriate credit to the original author(s) and the source, provide a link to the Creative Commons licence, and indicate if changes were made. The images or other third party material in this article are included in the article's Creative Commons licence, unless indicated otherwise in a credit line to the material. If material is not included in the article's Creative Commons licence and your intended use is not permitted by statutory regulation or exceeds the permitted use, you will need to obtain permission directly from the copyright holder. To view a copy of this licence, visit http://creativecommons.org/licenses/by/4.0/.

\section{References}

Allcott H (2011) Social norms and energy conservation. J Public Econ 95(9-10):1082-1095

Ayres I, Raseman S, Shih A (2012) Evidence from two large field experiments that peer comparison feedback can reduce residential energy usage. J Law Econ Organ 29:992

Brenkert-Smith H (2010) Building bridges to fight fire: the role of informal social interactions in six Colorado wildland-urban interface communities. Int J Wildland Fire 19(6):689-697

Brenkert-Smith H (2011) Homeowners' perspectives on the parcel approach to wildland fire mitigation: the role of community context in two colorado communities. J Forest 109(4):193-200

Brenkert-Smith H, Dickinson KL, Champ P, Flores N (2013) Social amplification of wildfire risk: the role of social interactions and information sources. J Risk Anal 33(5):800-817

Brenkert-Smith H, Dickinson KL, Flores N (2018) Relevant recruiting for online survey participation. SAGE Res Methods Cases Part 2. https://doi.org/10.4135/9781526438027

Brock WA, Durlauf SN (2001) Discrete choice with social interactions. Rev Econ Stud 68(2):235-260

Cialdini RB, Reno RR, Kallgren CA (1990) A focus theory of normative conduct: recycling the concept of norms to reduce littering in public places. J Pers Soc Psychol 58(6):1015

Cialdini RB, Kallgren CA, Reno RR (1991) A focus theory of normative conduct: a theoretical refinement and reevaluation of the role of norms in human behavior. Adv Exp Soc Psychol 24:201-234

Cialdini R, Demaine L, Sagarin B, Barrett D, Rhoads K, Winter P (2006) Managing social norms for persuasive impact. Soc Influ 1(1):3

Cohen JD (2001) Wildland-urban fire- a different approach. In: Proceedings of the Firefigther Safety Summit, International Association of Wildland Fire, Missoula, MT, 6-8 November 2001

Cohen J (2008) The wildland-urban interface fire problem: A consequence of the fire exclusion paradigm. For History Today Fall:20-26

Council WFE (2014) The national strategy: the final phase in the development of the national cohesive wildland fire management strategy. Report

Croson R, Shang J (2008) The impact of downward social information on contribution decisions. Exp Econ 11(3):221-233

CSFS (2017) Colorado state forest service: Colorado wildfire risk assessment portal

Dennison PE, Brewer SC, Arnold JD, Moritz MA (2014) Large wildfire trends in the western united states, 1984-2011. Geophys Res Lett 41(8):2928-2933

Dickinson K, Brenkert-Smith H, Champ P, Flores N (2015) Catching fire? Social interactions, beliefs, and wildfire risk mitigation behaviors. Soc Nat Resour 28(8):807-824

Ferraro PJ, Price MK (2013) Using nonpecuniary strategies to influence behavior: evidence from a largescale field experiment. Rev Econ Stat 95(1):64-73 
Fischbacher U, Gachter S, Fehr E (2001) Are people conditionally cooperative? Evidence from a public goods experiment. Econ Lett 71(3):397-404

Fishbein M, Ajzen I (2010) Predicting and changing behavior: the reasoned action approach. Psychology Press, New York

Frey B, Meier S (2004) Social comparisons and pro-social behavior: testing "conditional cooperation" in a field experiment. Am Econ Rev 94(5):1717-1722

Goldstein NJ, Cialdini RB, Griskevicius V (2008) A room with a viewpoint: using social norms to motivate environmental conservation in hotels. J Consum Res 35(3):472-482

Hammer RB, Stewart SI, Radeloff VC (2009) Demographic trends, the wildland-urban interface, and wildfire management. Soc Nat Resour 22(8):777-782

Kallgren CA, Reno RR, Cialdini RB (2000) A focus theory of normative conduct: when norms do and do not affect behavior. Pers Soc Psychol Bull 26(8):1002-1012

Kasperson RE, Renn O, Slovic P, Brown HS, Emel J, Goble R, Kasperson JX, Ratick S (1988) The social amplification of risk: a conceptual framework. Risk Anal 8(2):177-187

Kroll S, Shafran A (2017) Spatial externalities in interdependent security games. Working paper

Kunreuther H, Heal G (2003) Interdependent security. J Risk Uncertain 26(2):231-249

Kunreuther H, Meyer R, Van den Bulte C (2004) Risk analysis for extreme events: economic incentives for reducing future losses. National Institute of Standards and Technology, US Department of Commerce, Gaithersburg, MD

Lion R, Meertens R, Bot I (2002) Priorities in information desire about unknown risks. Risk Anal 22(4):765-776

Manski CF (1993) Identification of endogenous social effects: the reflection problem. Rev Econ Stud 60(3):531-542

McCaffrey SM, Stidham M, Toman E, Shindler B (2011) Outreach programs, peer pressure, and common sense: what motivates homeowners to mitigate wildfire risk? Environ Manag 48(3):475-488

Meldrum JR, Brenkert-Smith H, Champ PA, Falk L, Wilson P, Barth CM (2018) Wildland-urban interface residents' relationships with wildfire: variation within and across communities. Soc Nat Resour 31(10): 1132-1148

Meyer R (2008) Lessons from the earthquake lab: an experimental analysis of learning from experience about natural hazards. Public Entity Risk Institute, pp 19-34

Meyer R (2010) Development and pilot testing of a dynamic hurricane simulator for the laboratory study of hurricane preparedness and mitigation

Nelson KC, Monroe MC, Johnson JF (2005) The look of the land: homeowner landscape management and wildfire preparedness in Minnesota and Florida. Soc Nat Resour 18(4):321-336

NIFC.gov (2017a) National interagency fire center: historical wildland fire information: suppression costs (1985-2016)

NIFC.gov (2017b) National interagency fire center: weekly information report, 28 November 2017

NOAA (2012) State of the climate: wildfires, 7 August 2012

Ostrom E (1990) Governing the commons: the evolution of institutions for collective action. Cambridge University Press, New York

Ostrom E (2000) Collective action and the evolution of social norms. J Econ Perspect 14(3):137-158

Peterson CL, Vaske JJ (2016) Colorado residents' familiarity, aesthetic evaluations, and approval of forest management practices. J Forest 115(1):10-15

Pronin E, Berger J, Molouki S (2007) Alone in a crowd of sheep: asymmetric perceptions of conformity and their roots in an introspection illusion. J Pers Soc Psychol 92(4):585

Radeloff V, Stewart S, Hawbaker T, Gimmi U, Pidgeon A, Flather C, Hammer R, Helmers D (2010) Housing growth in and near United States protected areas limits their conservation value. Proc Natl Acad Sci 107(2):940

Reid CE, Brauer M, Johnston FH, Jerrett M, Balmes JR, Elliott CT (2016) Critical review of health impacts of wildfire smoke exposure. Environ Health Perspect 124(9):1334-1343

Sagat B, Patel JK, Lai KR, Griggs T, Arango T (2018) What's next after the camp fire destroyed paradise. New York Times, 26 December 2018

Schelling T (1978) Micromotives and macrobehavior. WW Norton and Company, New York

Schultz P, Nolan J, Cialdini R, Goldstein N, Griskevicius V (2007) The constructive, destructive, and reconstructive power of social norms. Psychol Sci 18(5):429

Sethi R, Somanathan E (1996) The evolution of social norms in common property resource use. Am Econ Rev 86(4):766-788

Shafran A (2008) Risk externalities and the problem of wildfire risk. J Urban Econ 64(2):488-495

Shafran A (2010) Interdependent security experiments. Econ Bull 30(3):1950-1962 
Short J (1984) The social fabric at risk: toward the social transformation of risk analysis. Am Sociol Rev 49(6):711-725

Soetevent AR (2006) Empirics of the identification of social interactions; an evaluation of the approaches and their results. J Econ Surv 20(2):193-228

Taylor MH, Christman L, Rollins K (2015) Choosing the right policy to promote defensible space in the wildfire-urban interface: evidence from homeowners in Nevada. UNR Economics Working Paper Series. Working Paper No. 15-001

Turner R, Nigg J, Heller-Paz D, Young B (1980) Community response to earthquake threat in Southern California. Institute for Social Science Research, University of California, Los Angeles, Los Angeles, CA

Warziniack T, Champ P, Meldrum J, Brenkert-Smith H, Barth CM, Falk LC (2019) Responding to risky neighbors: testing for spatial spillover effects for defensible space in a fire-prone WUI community. Environ Resour Econ 73(4):1023-1047

Weber JM, Kopelman S, Messick DM (2004) A conceptual review of decision making in social dilemmas: applying a logic of appropriateness. Pers Soc Psychol Rev 8(3):281-307

Westerling A, Swetnam T (2003) Interannual to decadal drought and wildfire in the western United States. EOS 84(49):545-554

Wolfe A (1993) Risk communication in social context: improving effective communication. Environ Prof $15(3)$

Publisher's Note Springer Nature remains neutral with regard to jurisdictional claims in published maps and institutional affiliations. 